\title{
Double labelling immunohistochemical characterization of autonomic sympathetic neurons innervating the sow retractor clitoridis muscle
}

\author{
L. Ragionieri, ${ }^{1}$ M. Botti, ${ }^{1}$ F. Gazza, ${ }^{1}$ L. Bo Minelli, ${ }^{1}$ F. Acone, ${ }^{2}$ R. Panu, ${ }^{1}$ G. Palmieri, ${ }^{2}$ \\ ${ }^{1}$ Department of Animal Health, Faculty of Veterinary Medicine, University of Parma; ${ }^{2}$ Department of \\ Animal Biology, Faculty of Veterinary Medicine, University of Sassari, Italy
}

ili

(C)2008 European Journal of Histochemistry

Retrograde neuronal tracing and immunohistochemical methods were used to define the neurochemical content of sympathetic neurons projecting to the sow retractor clitoridis muscle (RCM). Differently from the other smooth muscles of genital organs, the RCM is an isolated muscle that is tonically contracted in the rest phase and relaxed in the active phase. This peculiarity makes it an interesting experimental model.

The fluorescent tracer fast blue was injected into the RCM of three $50 \mathrm{~kg}$ subjects. After a one-week survival period, the ipsilateral paravertebral ganglion $\mathrm{S} 1$, that in a preliminary study showed the greatest number of cells projecting to the muscle, was collected from each animal. The co-existence of tyrosine hydroxylase with choline acetyltransferase, neuronal nitric oxide synthase, calcitonin gene-related peptide, leuenkephalin, neuropeptide $Y$, substance $P$ and vasoactive intestinal polypeptide was studied under a fluorescent microscope on cryostat sections. Tyrosine hydroxylase was present in about $58 \%$ of the neurons projecting to the muscle and was found to be co-localized with each of the other tested substances. Within fast blue-labelled cells negative to the adrenergic marker, small populations of neurons singularly containing each of the other enzymatic markers or peptides were also observed.

The present study documents the complexity of the neurochemical interactions that regulate the activity of the smooth myocytes of the RCM and their vascular components.

Key words: immunohistochemistry, retrograde tracing, peripheral autonomic neurons, genital smooth muscle, vascular smooth muscle, pig.

Correspondence: L. Ragionieri

Department of Animal Health, Faculty Veterinary Medicine

University of Parma, Via del Taglio, 8

43100 Parma, Italy

Tel.: +39.0521.032644.

Fax: +39.0521 .032642$

E-mail: luisa.ragionieri@unipr.it

Paper accepted on October 31, 2007

European Journal of Histochemistry

2008; vol. 52 issue 1 (Jan-Mar): 29-38
We retractor clitoridis muscle ( $R C M)$, absent in primates, dogs and some rodents, is a paired band of smooth muscle that in the sow originates directly from the smooth muscle of the anus and terminates at the base of the clitoris.

Differently from the other smooth muscles of genital organs, it does not form one of their layers, nor is it a component of their fibromuscular stroma. Moreover, the RCM is in tonic contraction in the rest phase and relaxed in the active phase. This peculiarity, and the fact that the muscle is easily identifiable and of simple and versatile preparation, makes it an interesting experimental model which we have been employing for the past several years to define its innervation. Using the Bielschowsky method and gold chloride or silver impregnation techniques (Panu et al., 1995), we demonstrated the presence of vegetative and sensory innervation in the RCM of some ungulates (sow, ewe, goat, mare) in fascial connective tissue. With the use of the retrograde neuronal tracer fast blue ( $F B$ ) (Panu et al., 2001) we also demonstrated that the peripheral autonomic and sensory neurons innervating the sow RCM are localized bilaterally in the lumbosacral paravertebral ganglia (PaG) and in the caudal mesenteric ganglia (CMG), and ipsilaterally in the sacral dorsal root ganglia (DRG). Moreover, by combining $\mathrm{FB}$ and single labelling immunofluorescence methods (Bo Minelli et al., 2002a), we performed a screening that revealed the presence of several biologically active substances within the sow RCM-projecting neurons. In this screening, tyrosine hydroxylase $(\mathrm{TH})$, the rate limiting enzyme of catecholamine synthesis, was shown to be the most abundant substance. By double labelling immunofluorescence methods (Gazza et al., 2005), we tentatively concluded that TH-immunoreactive (-IR) fibres amply supplied both the smooth myocites of the sow RCM and its blood vessels and that, in some cases, they also contained neuropeptide Y (NPY).

On the basis of these data, the present study was 
aimed at defining, within the neurons of the S1 paravertebral ganglion ( $P a G S 1$ ), (shown to contain the highest number of sympathetic neurons supplying the muscle (Panu et al., 2001)), the pattern and the percentage of co-existence of $\mathrm{TH}$, with: 1 choline acetyltransferase (ChAT), a marker of cholinergic neurons, 2, neuronal nitric oxide synthase (nNOS), a marker of nitric oxide, and 3, one of the following biologically active peptides, i.e. calcitonin gene related peptide (CGRP), leucineenkephalin (LENK), neuropeptide $Y$ (NPY), substance $P(S P)$ and vasoactive intestinal peptide (VIP).

This study was carried out in the swine a species which is frequently used as a research model (Kaleczyc et al., 1993, 1997; Majewski et al., 1995, 1999).

Preliminary data of this investigation have been published in abstract form (Bo Minelli et al., 2002b).

\section{Materials and Methods}

All procedures were approved by the local Ethics Committee for Animal Experimentation and by the Italian Ministry of Health. Precautions aimed at avoiding unnecessary suffering were taken at all stages of the experiment.

The study was carried out on the RCM of three $50 \mathrm{~kg}$ sows combining the retrograde neuronal tracer FB and double labelling immunofluorescence techniques.

The central part of the left RCM of each animal, under general anaesthesia, was inoculated with 50 $\mu l$ of $2 \% \mathrm{w} / \mathrm{v} F B$, a fluorescent tracer with cytoplasmatic affinity, by the use of a Hamilton syringe.

After a 7-day survival time, the animals, under general anaesthesia, were intracardially perfused, first with heparinized physiological solution and afterwards with fixative solution $(4 \% \mathrm{w} / \mathrm{v}$ paraformaldehyde in $0.1 \mathrm{M}$ phosphate buffer (PBS), pH 7.4). Before collecting the samples, macroscopic and microscopic examination of the $\mathrm{RCM}$ and adjacent tissues revealed that the distribution of FB was confined to the muscle and no evidence of the tracer in the surrounding tissues was found. This confirmed that the fascial connective tissue of the muscle represents a barrier capable of preventing the dispersion of the tracer in the surrounding tissues.
The ipsilateral PaG S1 was removed from each animal, post-fixed by immersion in the same fixative for $2 \mathrm{hr}$ at $4^{\circ} \mathrm{C}$, rinsed with $\mathrm{PBS}, \mathrm{pH} 7.4$ and transferred into a $10 \% \mathrm{~W} / \mathrm{v}$ buffered sucrose solution ( $\mathrm{pH}$ 7.4) for $24 \mathrm{~h}$. Afterwards, they were transferred into a $30 \% \mathrm{w} / \mathrm{v}$ buffered sucrose solution $(\mathrm{pH} 7.4)$ where they were stored at $4^{\circ} \mathrm{C}$ for at least three days or until further processing.

Each ganglion was placed flat in the cryostat mould and serially cut along its longest axis, in order to obtain a large number of cells per section.

The $12 \mu \mathrm{m}$ thick sections were stained by a double labelling immunofluorescence method to test the occurrence and co-localization of $\mathrm{TH}$ with ChAT, nNOS, CGRP, LENK, NPY, SP and VIP.

The same combinations of primary antisera were applied to sections at least $96 \mu \mathrm{m}$ away from each other to eliminate the likelihood of testing the same neuron twice for the same antisera. After air-drying at room temperature ( $r t$ ) for $30 \mathrm{~min}$, the sections were incubated with a solution containing $0.25 \%$ Triton X-100, 1\% bovine serum albumin and 10\% normal goat serum in PBS for $1 \mathrm{hr}(\mathrm{rt})$, to reduce non-specific background staining. They were then incubated with the combination of primary antisera (overnight, rt), further incubated with a mixture of fluorescein isothiocyanate (FITC)-conjugated goat antirabbit IgG and biotinylated-goat anti-mouse IgG ( $1 \mathrm{hr} ; \mathrm{rt}$ ) and, finally, incubated with Texas Red-conjugated streptavidin (primary antisera and secondary reagents are listed in Table 1) and mounted in buffered glycerin (Bio-Optica). Each step of immunolabelling was followed by rinsing the sections with PBS ( $3 \times 5$ min; $\mathrm{pH} 7.4$ ). In control experiments, no immunoreactivity was detected in sections incubated in the absence of primary antisera, replaced by PBS, and in sections incubated with the rabbit antisera which had been adsorbed with excess $(100 \mu \mathrm{g} / \mathrm{mL})$ of the respective antigens, when these were available [rat CGRP (Sigma), porcine NPY (Sigma), synthetic VIP (Sigma)].

The labelled sections were studied and photographed with a Zeiss Axioskop 2 plus fluorescence microscope equipped with epi-illumination and appropriate filter for FB (excitation wavelength 390-420 nm; emission wavelength $450 \mathrm{~nm}$ ), FITC (excitation wavelength $450-490 \mathrm{~nm}$; emission wavelength 515-565 nm) and Texas Red (excitation wavelength 530-585 nm; emission wavelength $615 \mathrm{~nm}$ ). Relationships between FB distribu- 
tion and immunohistochemical staining were examined directly by interchanging filters. The observations were made by a single operator.

In each ganglion, the relative percentages of RCM-projecting neurons containing different combinations of the markers were calculated on the total number of $\mathrm{FB}$-labelled $\left(\mathrm{FB}^{+}\right)$cells tested for each couple of primary antisera. Data are expressed as means \pm S.E.M.

\section{Results}

Each combination of primary antisera was tested on a mean number of $179.05 \pm 12.93 \mathrm{FB}+$ neurons of the PaG S1 from each animal. 57.91 $\pm 10.03 \%$ of the $\mathrm{FB}^{+}$neurons showed TH-IR. The immunofluorescence varied from strong to moderate and was uniformly distributed through the perikarya, sometimes also being evident along the neuronal processes.

Double labelling immunofluorescence showed that $\mathrm{TH}$ was co-localized in different proportions with each one of the other tested substances (Table 2).
NPY showed the highest percentage (34.14 $\pm 6.83 \%, n=167 \pm 30.75)$ of co-localization with TH (Figure 1, A1-A3). The neuronal cell bodies immunoreactive (IR) for NPY showed a granular labelling. These cell bodies were randomly distributed throughout the ganglion, sometimes forming small cell groups, but in general they were seen as single perikarya. Many of them had IR processes.

$\mathrm{TH}$ and $\mathrm{nNOS}$ were co-localized in a lower proportion $(6.90 \pm 3.18 \% ; n=185.33 \pm 40.34)$. A similar percentage of co-localization was found for $\mathrm{TH}$ and SP $(6.76 \pm 5.11 \% ; n=178 \pm 41.02)$, but was observed only in two of the three subjects. The immunofluorescent labelling of both nNOS-IR (Figure 1, B1-B3) and SP-IR (Figure 1, C1-C3) cells was uniformely distributed throughout the perikarya.

The percentage of co-localization found for $\mathrm{TH}$ and LENK was $4.49 \pm 2.86 \% \quad(n=210.67 \pm 54.77$, Figure 1, D1-D3). Similarly, the proportion of colocalization found for TH and ChAT was $4.28 \pm 2.16 \%(n=179 \pm 39.25$; Figure 1, El-E3), but this co-existence was observed only in two sub-

Table 1. Antisera and dilutions used in the experiments.

\begin{tabular}{|c|c|c|c|c|}
\hline Primary antisera & Raised in & Code no. & Supplier & Dilution \\
\hline Anti-tyrosine hydroxylase $(\mathrm{TH})$ & mouse (monoclonal) & Т 2928 & Sigma, St. Louis, Missouri, U.S.A. & $1: 4000$ \\
\hline Anti-choline acetyltransferase (ChAT) & rabbit (polyclonal) & AB 5042 & Chemicon International, Inc., Temecula, CA & $1: 3000$ \\
\hline Anti-neuronal nitric oxide synthase (n-NOS) & rabbit (polyclonal) & AB 5380 & Chemicon International, Inc., Temecula, CA & $1: 1500$ \\
\hline Anti-calcitonin gene related peptide (CGRP) & rabbit (polyclonal) & C 8198 & Sigma, St. Louis, Missouri, U.S.A. & $1: 4000$ \\
\hline Anti-leu-enkephalin (LENK) & rabbit (polyclonal) & L 8516 & Sigma, St. Louis, Missouri, U.S.A. & $1: 5$ \\
\hline Anti-neuropeptide Y (NPY) & rabbit (polyclonal) & N 9528 & Sigma, St. Louis, Missouri, U.S.A. & $1: 4000$ \\
\hline Anti-substance P (SP) & rabbit (polyclonal) & S 1542 & Sigma, St. Louis, Missouri, U.S.A. & $1: 4000$ \\
\hline Anti-vasoactive intestinal polypeptide (VIP) & rabbit (polyclonal) & V 3508 & Sigma, St. Louis, Missouri, U.S.A. & $1: 4000$ \\
\hline \multicolumn{5}{|l|}{ Secondary antisera } \\
\hline Anti rabbit lgG/FITC & goat & F 0382 & Sigma, St. Louis, Missouri, U.S.A. & $1: 40$ \\
\hline Anti mouse lgG/biotin & sheep & RPN 1001 & Amersham Pharmacia Biotech, U.K. & $1: 100$ \\
\hline Streptavidin/Texas red & & RPN 1233 & Amersham Pharmacia Biotech, U.K. & $1: 100$ \\
\hline
\end{tabular}

Table 2. Number (No.) of RPM-projecting (FB+) cells tested for each pair of primary antisera and relative percentages (RP) of FB+ neurons showing different combination of positivity to each pair of tested primary antisera. Data are expressed as means \pm S.E.M.

\begin{tabular}{|c|c|c|c|c|c|}
\hline Tested combination of primary antisera & $T H^{+} / A b^{+}(R P)$ & $T H^{+} / A b^{-}(R P)$ & $T H / A b^{+}(R P)$ & $T H / A b^{-}(R P)$ & $\mathrm{FB}^{+}$tested cells (No.) \\
\hline TH-CGRP & $3.10 \pm 1.74 \%$ & $63.64 \pm 7.33 \%$ & $0.34 \pm 0.18 \%$ & $32.93 \pm 8.99 \%$ & $173.33 \pm 38.85$ \\
\hline TH-LENK & $4.49 \pm 2.86 \%$ & $55.69 \pm 6.11 \%$ & $1.86 \pm 1.45 \%$ & $37.96 \pm 5.57 \%$ & $210.67 \pm 54.77$ \\
\hline TH-nNOS & $6.90 \pm 3.18 \%$ & $49.92 \pm 11.36 \%$ & $2.53 \pm 1.34 \%$ & $40.65 \pm 11.95 \%$ & $185.33 \pm 40.34$ \\
\hline TH-NPY & $34.14 \pm 6.83 \%$ & $28.28 \pm 2.92 \%$ & $11.10 \pm 1.71 \%$ & $26.49 \pm 10.76 \%$ & $167 \pm 30.75$ \\
\hline TH-SP & $6.76 \pm 5.11 \%$ & $54.33 \pm 5.37 \%$ & $0.00 \pm 0.00 \%$ & $38.91 \pm 9.53 \%$ & $178 \pm 41.02$ \\
\hline TH-ChAT & $4.28 \pm 2.16 \%$ & $55.49 \pm 5.85 \%$ & $0.55 \pm 0.37 \%$ & $39.68 \pm 7.92 \%$ & $179 \pm 39.25$ \\
\hline TH-VIP & $2.48 \pm 2.48 \%$ & $49.54 \pm 10.66 \%$ & $0.00 \pm 0.00 \%$ & $47.98 \pm 13.14 \%$ & $160 \pm 24.56$ \\
\hline
\end{tabular}



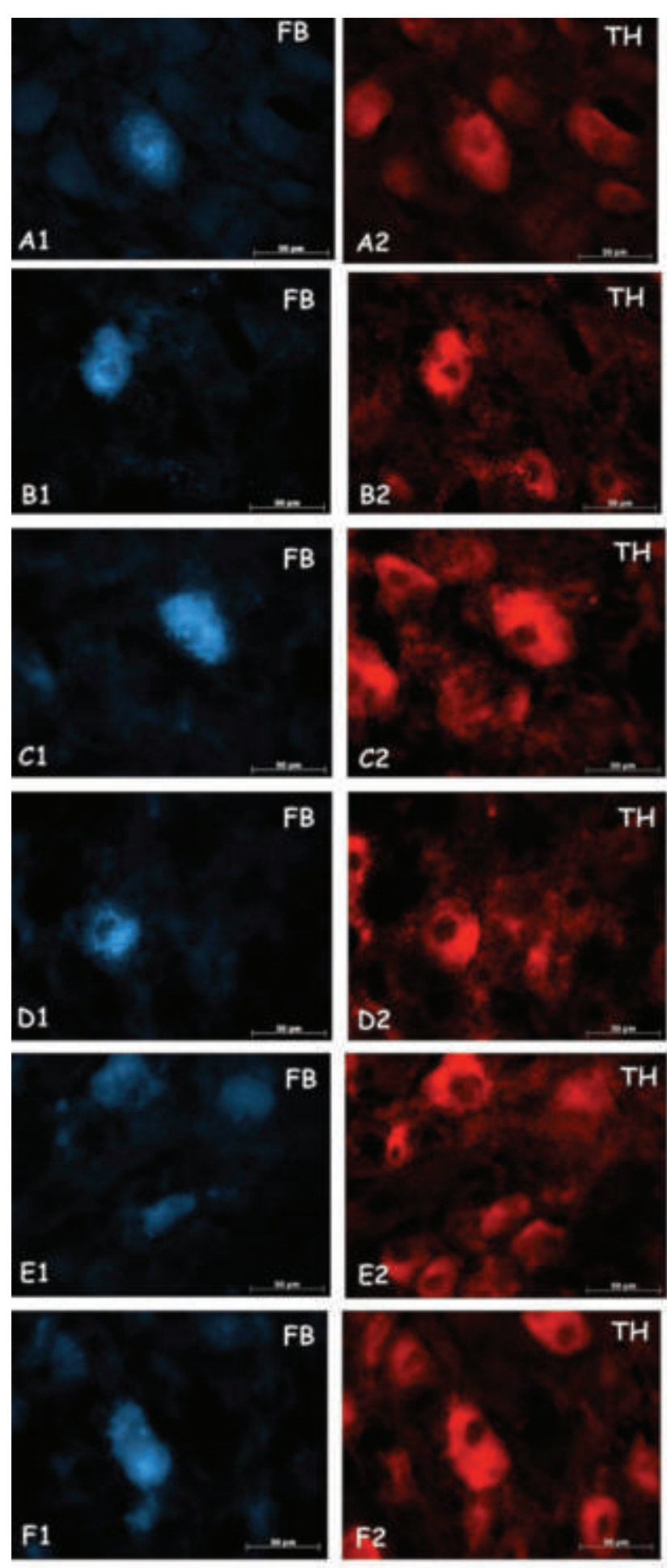

E3
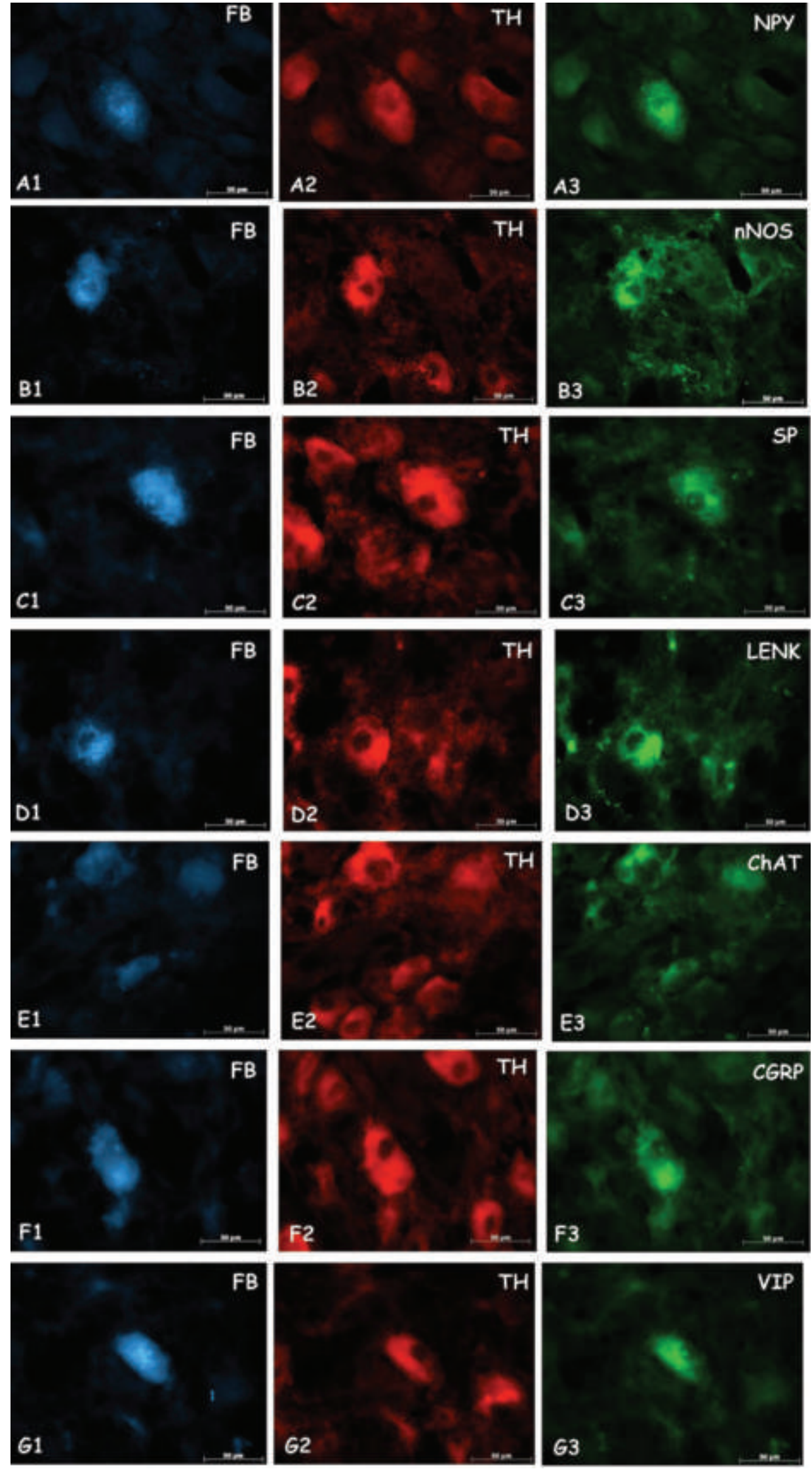

CGRP
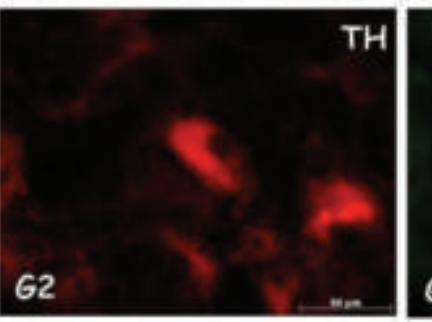

(

VIP

G2

63

Figure 1. Fluorescence micrographs of PaG S1 $\mathrm{FB}^{+}$cells showing positivity to the different couples of tested antisera

Respectively: $\mathrm{A}=$ a $\mathrm{FB}^{+}$cell (A1) showing also positivity to TH (A2) and NPY (A3); B= a $\mathrm{FB}^{+}$cell (B1) showing also positivity to TH (B2) and nNOS (B3); $\mathrm{C}=$ a $\mathrm{FB}^{+}$cell (C1) showing also positivity to TH (C2) and SP (C3); $D=a F^{+}$cell (D1) showing also positivity to TH (D2) and LENK (D3); $E=$ three $\mathrm{FB}^{+}$cells (E1) showing also positivity to TH (E2) and ChAT (E3); $F=$ a $F^{+}$cell (F1) showing also positivity to TH (F2) and CGRP (F3); G= a FB ${ }^{+}$cell (G1) showing also positivity to TH (G2) and VIP (G3). Scale bar $=50 \mu \mathrm{m}$. Magnification, 40X 
jects, as was that of the TH and CGRP co-localization (3.10 $1.74 \%, n=173.33 \pm 38.85$; Figure 1, F1-F3); while the co-existence of TH and VIP was detected in only one subject $(2.48 \pm 2.48 \%$, $\mathrm{n}=160 \pm 24.56$; Figure 1, G1-G3).

Among $\mathrm{FB}^{+}$paravertebral non-catecholaminergic neurons, a discrete proportion was NPY-IR $(11.10 \pm 1.71 \%)$, while smaller percentages of cells were nNOS-IR $(2.53 \pm 1.34 \%)$ or LENK-IR $(1.86 \pm 1.45 \%)$. Very few neurons exhibited immunoreactivity for ChAT $(0.55 \pm 0.37 \%)$ or CGRP $(0.34 \pm 0.18 \%)$. No non-catecholaminergic RCM-projecting neuron, in the studied ganglia, showed immunoreactivity for VIP or for SP alone.

\section{Discussion}

\section{TH-immunoreactivity}

On the basis of the presence of the catecholamine-synthetizing enzyme ( $\mathrm{TH})$, the majority of the autonomic paravertebral RCM-projecting neurons is catecholaminergic in character. These neurons are probably the major source of the high number of TH-IR fibers that we have previously found in the RCM (Gazza et al., 2005).

However, among the $\mathrm{FB}^{+}$tested cells, there was a conspicuous population of neurons that did not express positivity to $\mathrm{TH}$ and that therefore, should be considered either cholinergic or non-catecholaminergic/non cholinergic in character.

Noradrenaline is excitatory in nature and causes contraction of smooth muscle cells (Owman and Stjernquist, 1988; Keast, 1999; Andersson, 2000). As noradrenergic fibers are usually found in the muscular coat or around blood vessels of genital organs (Kaleczyc et al., 1993; Czaja et al., 1996; Andersson and Stief, 1997), and of the RCM in particular (Gazza et al., 2005), it may be concluded that the TH-IR RCM-projecting neurons exert the same influence both on the smooth muscle cells of the muscle and its blood vessels.

\section{NPY-immunoreactivity}

NPY was the substance that showed the highest proportion of co-localization with TH. Our previous observations (Gazza et al., 2005) of high numbers of TH/NPY-IR fibers in the sow RCM are in accordance with the present finding. Moreover, high levels of NPY in noradrenergic neurons have already been found by Lundberg et al. (1983) and by
Klimczuk (2004) in the male pig sympathetic paravertebral neurons.

In the present study, NPY-immunoreactivity was also found in a significant number of TH-negative ( $\mathrm{TH}-$ ) neurons innervating the porcine RCM. This is in accordance with the proportion of NPY-containing cells ( $5-10 \%$ of the gangliar neurons) found by Lakomy et al. (1994) in the thoraco-lumbar paravertebral ganglia of female piglets.

Our finding is not only in agreement with the large number of NPY-IR nerve fibres observed in the RCM (Gazza et al., 2005), but also, more generally, in different porcine female genital organs such as the uterus, oviduct and ovary (Häppölä et al., 1991).

Since NPY is a potent vasoconstrictor of many mammalian arteries (McLachlan and LlewellynSmith, 1986; Lindh et al., 1989; Lundberg et al., 1990), these NPY-positive neurons, whether containing TH or not, could play a role in blood flow regulation (Gibbins, 1991, Lundberg et al., 1983). Moreover, in the female, NPY also regulates the contractile activity of non-vascular smooth muscle cells of the uterus and oviduct, as well as the secretory function of the ovary (Markiewicz et al., 2003). These regulatory functions might be performed by inhibiting the release of acetylcholine (ACh) from cholinergic nerve endings by a presynaptic mechanism (Stjernquist et al., 1987; Lundberg et al., 1990), or by enhancing the contractile effects of noradrenaline directly affecting postsynaptic receptors (Ekblad et al., 1984).

\section{nNOS-immunoreactivity}

In the present study, nNOS showed a moderate degree of co-localization with $\mathrm{TH}$ within the porcine paravertebral RCM-projecting neurons. This type of immunoreactivity has not been observed either in the nerve fibres supplying the sow RCM (Gazza et al., 2005) or in the fibers and neurons innervating the porcine female reproductive organs (Majewski et al., 1995). Differently, the co-localization of nNOS with TH had earlier been observed in some paravertebral neurons projecting to the bulbospongiosus muscle of the male pig (Gazza et al., 2003) and, but only exceptional$l y$, in a very small number of paravertebral neurons of the cat (Anderson et al., 1995), guinea-pig (Fischer et al., 1996), and man (Klimaschewski et al., 1996). Finally NOS has been shown to be colocalized with dopamine-beta-hydroxylase $(D \beta H)$ 
in the dopaminergic neurons of the bovine cranial cervical ganglion (Sheng et al., 1993).

We have detected nNOS-immunoreactivity also in a small number of $\mathrm{TH}$ neurons projecting to the RCM. This immunoreactivity has already been demonstrated in a small number of paravertebral neurons supplying the gilt genital organs (Majewski et al., 1995), and in non-noradrenergic cells (Anderson et al., 1995; Fischer et al., 1996), where nNOS is often co-localized with VIP or NPY.

In the porcine female genital organs, Majewski et al. (1995) found high numbers of nNOS-IR fibers only in the ovary and moderate numbers of nitrergic fibers in the oviduct, uterus and vagina. These results indicated that NO is particularly involved in the regulation of blood flow through the porcine reproductive tract. It may be postulated that $\mathrm{NO}$ also exerts its well known relaxing activity on the smooth muscle cells of the RCM, in addition to causing vasodilatation of its blood vessels. On the other hand, in its co-existence with $\mathrm{TH}$, might play a role of modulator. In fact, it seems seem to lead to an increase in TH activity in postganglionic neurons via both cyclic GMP-dependent and -independent mechanisms (Klimaschewski et al., 1996).

\section{SP-immunoreactivity}

We found a moderate degree of co-localization of SP with TH in porcine paravertebral RCM-projecting neurons. This is an unexpected finding because no co-localization of SP with $\mathrm{TH}$ was observed in the nerve fibres supplying the sow RCM (Gazza et al., 2005) and, more generally, SP has never been found co-localized with noradrenergic markers in neurons of the female pig sympathetic paravertebral ganglia (Majewski et al., 1995; Wasowicz, 2003). Nevertheless, immunoreactivity to both TH and SP has been observed in a small percentage of paravertebral neurons projecting to the pig bulbospongiosus muscle (Gazza et al., 2003), in moderate numbers of neurons of the porcine urinary bladder trigone intramural ganglia (Pidsudko, 2004) and in the majority of the principal neurons of the rat superior cervical ganglion (Bohn et al., 1984).

In the present study, no positivity for SP has been found in non-catecholaminergic neurons. Although SP has always been considered to be absent in neurons of pig paravertebral ganglia
(Häppölä et al., 1993; Lakomy et al., 1994), it has been demonstrated to be present in a very small number of paravertebral neurons projecting to the pig retractor penis muscle (Botti et al., 2006). Among other species, SP has been noticed only in the stellate ganglion of water buffalo (Nasu et al., 2000) and cattle (Nasu et al., 2003).

However, since some studies support the supposition that the failure to find SP may be due to the methods used, which might not be sensitive enough to detect minute amounts of intracytoplasmic SP (Lindh et al., 1989, Häppölä et al., 1993), we would conclude that our data need further investigations. If confirmed, the putative physiological significance of the co-existence of $\mathrm{TH}$ and $\mathrm{SP}$ in genital organs might be that they play a role in several visceral reflexes and neuroendocrine responses (Traurig et al., 1991; Majewski et al., 1995).

\section{LENK-immunoreactivity}

We found immunoreactivity for LENK, an enkephalin belonging to the opioid peptides family, in a fair number of catecholaminergic RCM-projecting cells of the PaG Sl. The coexistence of LENK or other enkephalins with TH in pig paravertebral neurons has been observed only in some neurons projecting to the bulbospongiosus muscle (Gazza et al., 2003), but opioid peptides have been detected in noradrenergic nerve terminals supplying both the muscle layer and some arteries of the porcine oviduct (Czaja et al., 1996).

We also found LENK immunoreactivity in a small number of $\mathrm{FB}^{+} / \mathrm{TH}^{-}$neurons of the $\mathrm{PaG} \mathrm{SI}$. In the pig, the presence of opioid peptides has been noticed in neurons of the cervical (Häppölä et al., 1993), thoraco-lumbar (Lakomy et al., 1994) and sacral (Gazza et al., 2003; Botti et al., 2006) paravertebral ganglia, independently of the presence of TH. Moreover, LENK-immunoreactivity has been found in nerve processes in the interstitial connective tissue of the sow RCM (Gazza et al., 2005) and, in general, opioid peptides have been seen in fibres innervating the pig female genital organs (Czaja et al. 1996).

The LEN K-containing neurons might have a regulatory role in neurotransmission in the RCM and its vessels. In fact, the coexistence of enkephalins with noradrenaline in sympathetic ganglia (Konishi et al., 1981) and in fibres innervating genital organs (De Potter et al., 1987) suggests that these peptides may presynaptically modulate sympathet- 
ic inputs at the neuro-effector junction (Czaja et al., 1996). The same coexistence, observed in several noradrenergic perivascular nerve fibers (Owman and Stjernquist, 1988), suggests that enkephalins might also have a vasodilator effect due to their inhibitory action on autonomic neurotransmission (Konishi et al., 1981; Kaleczyc et al., 1997; Kaleczyc, 1998).

\section{CGRP-immunoreactivity}

The present study proved the co-localization of CGRP with TH in a small number of RCM-projecting cells. Identically coding neurons have been already observed among the ones projecting to the pig bulbospongiosus muscle (Gazza et al., 2003) and in human paravertebral ganglia (Baffi et al., 1992). However, like SP, CGRP is a tachykinin commonly considered to be a marker of afferent pathways (Majewski et al., 1995; Kaleczyc et al., 1997; Czaja, 2000); therefore, its presence within paravertebral neurons is an unforeseen finding and its co-localization with $\mathrm{TH}$ even more so.

The detection of only two $\mathrm{TH}^{-} / \mathrm{CGRP}^{+}$neurons is another unexpected finding because CGRPimmunoreactivity has already been described in pig (Häppölä et al., 1993; Lakomy et al., 1994; Gazza et al., 2003), cat (Lindh et al., 1989) and horse (Nasu et al., 2003) paravertebral ganglia.

However, our data of a very small number of $C G P^{+}$neurons are in accordance with the infrequent findings of CGRP-IR fibers in the interstitial connective tissue of the sow RCM (Gazza et al., 2005) and in the homologous muscle of the male, the retractor penis muscle, where they principally supply arterial blood vessels (Majewski et al., 1999).

As there is some evidence that a minor proportion of CGRP-containing nerve fibres supplying human genital organs are noradrenergic autonomic structures (Jen et al., 1997), in accordance with Häppölä et al. (1993), we propose that they might play a functional role in the modulation of neurotransmission in the target organs of the porcine sympathetic ganglia.

\section{VIP-immunoreactivity}

We observed positivity for VIP only in a small number of $\mathrm{FB}^{+} / \mathrm{TH}^{+}$paravertebral neurons of one subject, while no non-noradrenergic neurons showed immunoreactivity for VIP. This datum is in agreement with the small number of VIP-IR fibres found in the interstitial connective tissue of the sow RCM (Gazza et al., 2005).

Until now, the co-localization of TH and VIP has been described only in sacral paravertebral neurons projecting to the pig bulbospongiosus muscle (Gazza et al., 2003). However, VIP has already been found in association with $\mathrm{D} \beta \mathrm{H}$ in some vasodilatory neurons of the porcine thoracic sympathetic chain ganglia (Hill and Elde, 1989; Majewski, 1999). The coexistence of TH and VIP is unusual for a peptide commonly thought to be a marker of the cholinergic pathway or a classical neurotransmitter of the inhibitory-non adrenergic/ non cholinergic (NANC) subdivision of the autonomic nervous system (Itoh et al., 1995).

In general, VIP-immunoreactivity has been found, with distinct cranio-caudal differences, in some neurons of the pig cervical (Häppölä et al., 1993), thoraco-lumbar (Hill and Elde; 1989; Lakomy et al., 1994) and sacral paravertebral ganglia (Botti et al., 2006).

VIP-ergic neurons play a role in blood flow regulation, because, like NO, VIP acts as vasodilator on genital organ blood vessels (Polak et al., 1981; Morris et al., 1985; Mayewski et al., 1995), and displays a physiological antagonism with NPY in the control of blood flow (Morris et al., 1985).

\section{ChAT-immunoreactivity}

The co-localization of cholinergic and catecholaminergic markers, detected in a small number of RCM projecting neurons has been observed only in paravertebral neurons projecting to the pig bulbospongiosus muscle (Gazza et al., 2003). On the other hand, ChAT and D $\beta H$ have been found colocalized in the foetal pig superior cervical ganglion (Wang et al., 1995). It is known that, during foetal development, some neurons transiently express the noradrenergic phenotype but they subsequently lose their noradrenergic characteristics, becoming cholinergic cells (Schäfer et al., 1997; Keast, 1999; Masliukov and Timmermans, 2004). If so, we may suggest that, in the gilt sympathetic neurons observed herein, the development of the cholinergic marker might not have been paralleled by a complete disappearance of the various catecholamine markers.

A very scarce number of non-catecholaminergic neurons projecting to the RCM were ChAT-IR. This finding is in accordance with the fact that only single cholinergic fibers have been observed in the 
interstitial connective tissue and in the muscular coat of the vessels of the pig RCM (Gazza et al., 2005) and of the male homologous retractor penis muscle (Majewski et al., 1999).

Only small groups of cholinergic neurons have also been observed among the paravertebral neurons projecting to the RPM in the male pig (Botti et al., 2006) and in the sympathetic chain ganglia of other species such as the cat (Lindh et al., 1989), rat (Schäfer et al., 1997) and man (Masliukov and Timmermans, 2004). This is in accordance with the fact that the cholinergic paravertebral neurons target principally eccrine sweat glands or hindlimb blood vessels (Majewski, 1999). The small number of cholinergic structures found in the above-mentioned studies might also be due to the limited availability and sensitivity of a suitable marker for cholinergic neurons in the peripheral nervous system (Kaleczyc, 1998; Klimczuk et al., 2005), or to the fact that single cholinergic nerve cell bodies and small acetylcholinesterase-positive ganglia are localized within the muscle itself, rather than in other autonomic ganglia, as has been shown in species such as the goat (Sjöstrand et al., 1993) or bull (Alaranta et al., 1989). Finally, in many species, including the pig, ChAT- and VAChT (vesicular acetylcholine transporter)-immunoreactivity are present in a number of endothelial cells (Haberberger et al., 2000). Therefore, there would be a second source of ACh that could take part in some regulatory mechanisms.

The principal function of cholinergic innervation in the urogenital system might be the presynaptic inhibition of the adrenergic excitatory neurotransmission (Klinge and Sjöstrand, 1977; Sjöstrand et al., 1993), and this could not require a high number of cholinergic neurons and nerve fibers, that, at least as far as the control of the blood flow is concerned, could be helped by the endothelial cells releasing $\mathrm{ACh}$.

\section{Conclusions}

The RCM is essentially an isolated bundle of smooth musculature that, differently from other smooth muscles associated with the genital organs, is not a layer of a tubular organ or a part of the fibromuscular stroma of a gland. For this reason, we can be sure that the neurons labelled by the ret- rograde tracer are the ones exclusively directed to the smooth myocytes of the RCM or of its vessels and to no other tissue component (e.g. glands) of a genital organ. The simplicity of the preparation and the reliability and reproducibility of the obtained data make the RCM a useful model for the study of the innervation of the smooth muscles associated with genital organs.

The present findings suggest that the neurons of the PaG S1, that mainly contributes to the sympathetic innervation of the sow RCM, is involved, first of all, in the maintaining of the muscle tonus of both non-vascular and vascular smooth myocytes. A minor proportion of gangliar paravertebral cells may participate to the modulation (regulation) of neurotransmission or they may act as inhibitory neurons on the activity of non-vascular smooth myocytes, while neurons with only a vasodilator function seem to be very scarce.

Finally, our findings seem to confirm the presence of a previously nearly unknown small population of CGRP- and SP-IR catecholaminergic sympathetic neurons, and indicate the existence of a small proportion of tachykinergic/non-catecholaminergic sympathetic neurons.

\section{References}

Alaranta S, Uusitalo H, Klinge E, Palkama A, Sjöstrand NO. Histochemical demonstration of nerve cell bodies in the retractor penis muscle and the penile artery of the bull. Neurosci 1989;32:823-27.

Anderson CR, McAllen RM, Edwards SL. Nitric oxide synthase and chemical coding in cat sympathetic postganglionic neurons. Neurosci 1995;68:255-64.

Andersson KE. Neurotransmitters:central and peripheral mechanisms. Int J Impot Res 2000;12(S4):S26-S33.

Andersson KE, Stief CG. Neurotransmission and the contraction and relaxation of penile erectile tissues. World J Urol 1997;15:14-20.

Baffi J, Görcs T, Slowik F, Horváth M, Lekka N, Pásztor E, Palkovits $M$. Neuropeptides in the human superior cervical ganglion. Brain Res 1992;570:272-8.

Bo Minelli L, Ragionieri L, Botti M, Gazza F, Acone F, Panu R, et al. Peripheral neurons projecting to genital smooth musculature in the female pig: experimental study by retrograde transport and immunohistochemistry. It J Anat Embryol 2002 a;107:87-101.

Bo Minelli L, Ragionieri L, Botti M, Gazza F, Acone F, Panu R, et al. Double labelling immunohistochemistry on the autonomic neurons projecting to the smooth genital musculature of the sow. Reproduction in Domestic Animals 2002 b; 37:227.

Bohn MC, Kessler JA, Adler JE, Markey K, Goldstein M, Black IB. Simultaneous expression of the SP-peptidergic and noradrenergic phenotypes in rat sympathetic neurons. Brain Res 1984;298:37881.

Botti M, Ragionieri L, Bo Minelli L, Gazza F, Acone F, Panu R, Palmieri G. Peripheral neurons innervating the extrinsic smooth penile muscolature of the pig:experimental study by retrograde transport and immunohistochemistry. It $J$ Anat Embryol 2006;111:182-8. 
Czaja K. Distribution of primary afferent neurons innervating the porcine oviduct and their immunohistochemical characterization. Cells Tissue Organs 2000;166:275-82.

Czaja K, Kaleczyc J, Sienkiewicz W, Majewski M, Lakomy M. Peptidergic innervation of the porcine oviduct studied by doublelabelling immunohistochemistry. Folia Histochem Cytobiol 1996;34:141-50.

De Potter WP, Coen EP, De Potter RW. Evidence for the coexistence and co-release of [Met] enkephalin and noradrenaline from sympathetic nerves of the bovine vas deferens. Neurosci 1987;20:85566.

Ekblad E, Edvinsson L, Wahlestedt C, Uddman R, Hakanson R, Sundler F. Neuropeptide $Y$ co-exists and co-operates with noradrenaline in perivascular nerve fibers. Regul Pept 1984;8:225-35.

Fischer A, Mayer B, Kummer W. Nitric oxide synthase in vagal sensory and sympathetic neurons innervating the guinea-pig trachea. J Auton Nerv Syst 1996;56:157-60.

Gazza F, Acone F, Botti M, Ragionieri L, Panu R, Bo Minelli L, et al. Double labelling immunohistochemistry on the peripheral autonomic neurons projecting to the bulbospongiosus muscle in male impuberal pigs. Vet Res Commun 2003;27 Suppl 1:603-05.

Gazza F, Botti M, Minelli LB, Ragionieri L, Acone F, Panu R, et al. Double labelling immunohistochemistry on the nerve fibres of retractor clitoridis muscle of the sow. Vet Res Commun 2005;29 Suppl 2:191-94.

Gibbins IL. Vasomotor, pilomotor and secretomotor neurons distinguished by size and neuropeptide content in superior cervical ganglia of mice. J Auton Nerv Syst 1991;34:171-83.

Haberberger RV, Bodenbenner M, Kummer W. Expression of the cholinergic gene locus in pulmonary arterial endothelial cells. Histochem Cell Biol 2000;113:379-87.

Häppölä 0, Lakomy M, Majewski M, Yanaihara N. Distribution of somatostatin- and neuropeptide $\mathrm{Y}$-immunoreactive nerve fibers in the porcine female reproductive system. Neurosci Lett $1991 ; 122: 273-6$

Häppölä 0, Lakomy M, Majewski M, Wasowicz K, Yanaihara N. Distribution of neuropeptides in the porcine stellate ganglion. Cell Tissue Res 1993;274:181-7.

Hill EL, Elde R. Vasoactive intestinal peptide distribution and colocalization with dopamine-beta-hydroxylase in sympathetic chain ganglia of pig. J Auton Nerv Syst 1989;27:229-39.

Itoh $\mathrm{H}$, Sakai J, Imoto $A$, Creed KE. The control of smooth muscle tissues by nonadrenergic noncholinergic (NANC) nerve fibres in the autonomic nervous system. J Smooth Muscle Res 1995;31:67-78.

Jen PY, Dixon JS, Gosling JA. Co-localization of nitric oxide synthase, neuropeptides and tyrosine hydroxylase in nerves supplying the human post-natal vas deferens and seminal vesicle. $\mathrm{Br} \mathrm{J}$ Urol 1997;80:291-9.

Kaleczyc J. Origin and neurochemical characteristics of nerve fibres supplying the mammalian vas deferens. Micr Res And Techn 1998;42:409-22.

Kaleczyc J, Majewski M, Calka J, Lakomy M. Adrenergic innervation of the epididymis, vas deferens, accessory genital glands and urethra in the boar. Folia Histochem Cytobiol 1993;31:117-23.

Kaleczyc J, Timmermans JP, Majewski M, Lakomy M, Scheuermann DW. Immunohistochemical characteristics of nerve fibres supplying the porcine vas deferens. A colocalisation study. Histochem Cell Biol 1997;107:229-41.

Keast JR. Unusual autonomic ganglia: connections, chemistry, and plasticity of pelvic ganglia. Int Rev Cytol 1999;193:1-69.

Klimaschewski L, Kummer W, Heym C. Localization, regulation and functions of neurotransmitters and neuromodulators in cervical sympathetic ganglia. Microsc Res Tech 1996;35:44-68.

Klimczuk M. Immunohistochemical characteristics of neurons supplying the porcine bulbourethral gland. Pol J Vet Sci 2004;7:12942.

Klimczuk M, Kaleczyc J, Franke-Radowiecka A, Czaja K, Podlasz P, Lakomy M. Immunohistochemical characterisation of cholinergic nerve fibres supplying accessory genital glands in the pig. Vet Med Czech 2005;50:119-30.

Klinge $E$, Sjöstrand NO. Suppression of the excitatory adrenergic neurotransmission; a possible role of cholinergic nerves in the retractor penis muscle. Acta Physiol Scand 1977;100:368-76.

Konishi S, Tsuno A, Otsuka M. Enkephalin as transmitter for presynaptic inhibition in sympathetic ganglia. Nature 1981;294:80-82.

Lakomy M, Häppölä 0 , Kaleczyc J, Majewski M. Immunohistochemical localization of neuropeptides in the porcine thoraco-lumbar paravertebral ganglia. Anat Histol Embryol $1994 ; 23: 12-20$

Lindh B, Lundberg JM, Hökfelt T. NPY-, galanin-, VIP/PHI-, CGRPand substance $P$-immunoreactive neuronal subpopulations in cat autonomic and sensory ganglia and their projections. Cell Tissue Res 1989;256:259-73.

Lundberg J M, Terenius L, Hökfelt T, Goldstein M. High levels of neuropeptide $Y$ in peripheral noradrenergic neurons in various mammals including man. Neurosci Lett 1983;42:167-72.

Lundberg JM, Franco-Cereceda A, Lacroix JS, Pernow J. Neuropeptide $Y$ and sympathetic neurotransmission. Ann N Y Acad Sci 1990;611:166-74.

Majewski M. Synaptogenesis and structure of the autonomic ganglia. Folia Morphol (Warsz) 1999;58 (3 Suppl 2):65-99.

Majewski M, Sienkiewicz W, Kaleczyc J, Mayer B, Czaja K, Lakomy $M$. The distribution and co-localization of immunoreactivity to nitric oxide synthase, vasoactive intestinal polypeptide and substance $P$ within nerve fibres supplying bovine and porcine female genital organs. Cell Tissue Res 1995;281:445-64.

Majewski M, Kaleczyc J, Mayer B, Schemann M, Weihe E, Lakomy $M$. Innervation of the fibro-elastic type of the penis: an immunohistochemical study in the male pig. Acta Histochem 1999;101:71-101.

Markiewicz W, Jaroszewski JJ, Bossowska A, Majewski M. NPY: its occurrence and relevance in the female reproductive system. Folia Histochem Cytobiol 2003;41:183-92.

Masliukov PM, Timmermans JP. Immunocytochemical properties of stellate ganglion neurons during early postnatal development. Histochem Cell Biol 2004;122:201-09.

McLachlan EM, Llewellyn-Smith IJ. The immunohistochemical distribution of neuropeptide $Y$ in lumbar pre- and paravertebral sympathetic ganglia of the guinea pig. J Auton Nerv Syst 1986;17:313-24.

Morris JL, Gibbins IL, Furness JB, Costa M, Murphy R. Co-localization of neuropeptide $Y$, vasoactive intestinal polypeptide and dynorphin in non-noradrenergic axons of the guinea pig uterine artery. Neurosci Lett 1985;62:31-7.

Nasu T, De Ocampo G, Molina HA, Tateyama S, Morimoto M. Immunohistochemical study of the neuropeptides in the stellate ganglion of the water buffalo. Fukuoka Igaku Zasshi 2000;91:116-22.

Nasu T, Sueishi A, Morimoto M. Neuropeptide distribution in the stellate ganglia of the domestic animal. Fukuoka Igaku Zasshi 2003;94:338-46.

Owman C, Stjernquist M. Origin, distribution and functional aspects of aminergic and peptidergic nerves in the male and female reproductive tracts. In: Handbook of chemical neuroanatomy: The peripheral nervous system. Björklund A., Hökfelt T., Owman C., (Eds) Elsevier, Amsterdam 1988, pp 445-544.

Panu R, Bo Minelli L, Sanna L, Zedda M, Acone F, Gazza F, Palmieri $G$. On the vegetative and sensitive innervation of the Retractor clitoridis muscle in some domestic animals. Anat Histol Embryol $1995 ; 24: 265-8$.

Panu R, Bo Minelli L, Botti M, Gazza F, Acone F, Palmieri G. Peripheral ganglia supplying the genital smooth musculature in the female pig: an experimental study. J Anat 2001;199:317-22.

Pidsudko Z. Distribution and chemical coding of neurons in intramural ganglia of the porcine urinary bladder trigone. Folia Histochem Cytobiol 2004;42:3-11

Polak JM, Gu J, Mina S, Bloom SR. Vipergic nerves in the penis. Lancet $1981 ; 2: 217-9$.

Schäfer MKH, Schütz B, Weihe E, Eiden LE. Target-independent cholinergic differentiation in the rat sympathetic nervous system. Proc Natl Acad Sci USA 1997;94:4149-54.

Sheng $H$, Gagne GD, Matsumoto T, Miller MF, Forstermann U, Murad F. Nitric oxide synthase in bovine superior cervical ganglion. J Neurochem 1993;61:1120-6.

SjEstrand NO, Beckett SD, Klinge E. Nervous regulation of the tone 
of the retractor penis muscle in the goat. Acta Physiol Scand 1993; 147:403-15.

Stjernquist M, Owman C, Sjöberg NO, Sundler F. Coexistence and cooperation between neuropeptide $Y$ and norepinephrine in nerve fibers of guinea pig vas deferens and seminal vesicle. Biol Reprod 1987;36:149-55.

Traurig HH, Papka RE, Shew RL. Substance $P$ and related peptides associated with the afferent and autonomic innervation of the uterus. Ann N Y Acad Sci 1991;632:304-13.
Wang JM, Partoens PM, Callebaut DP, Coen EP, Martin JJ, De Potter WP. Phenotype plasticity and immunocytochemical evidence for ChAT and D beta $\mathrm{H}$ co-localization in fetal pig superior cervical ganglion cells. Brain Res Dev Brain Res 1995;90:17-23.

Wasowicz K. Changes in the expression of tyrosine hydroxylase (TH), dopamine beta-hydroxylase $(D B H)$, galanin $(G A L)$, vasoactive intestinal polypeptide (VIP) and substance $P$ (SP) in the uterine cervix-projecting neurons located in the lumbar paravertebral ganglia of the pig. Folia Morphol (Warsz) 2003;62:219-21. 